\title{
Commentary
}

\section{Keep swimming but stop peeing in the pools}

\author{
Qi Zheng ${ }^{1}$, Lindsay K. Jmaiff Blackstock ${ }^{2}$, Wenchao Deng ${ }^{1,3}$, Hailin Wang ${ }^{3}$, \\ $\mathrm{X}$. Chris $\mathrm{Le}^{2}$, Xing-Fang $\mathrm{Li}^{2}$,* \\ 1. Key Laboratory of Optoelectronic Chemical Materials and Devices, Ministry of Education, Institute of Environment and Health, \\ Jianghan University, Wuhan 430056, China \\ 2. Division of Analytical and Environmental Toxicology, Department of Laboratory Medicine and Pathology, Faculty of Medicine and Dentistry, \\ University of Alberta, Edmonton, Alberta, T6G 2G3, Canada \\ 3. State Key Laboratory of Environmental Chemistry and Ecotoxicology, Research Center for Eco-Environmental Sciences, \\ Chinese Academy of Sciences, Beijing 100085, China
}

\section{A R T I C L E I N F O}

Available online 12 March 2017

Keywords:

Swimming pool

Acesulfame potassium (ACE)

Artificial sweeteners

Disinfection byproducts (DBPs)

Dissolved organic carbon (DOC)

Human urine

Swimmer hygiene

Water quality

Swimming is excellent exercise and offers many health benefits. However, the "chlorine smell" in swimming pools may be a turn-off for some people. Although this smell is often thought to be of chlorine, it actually comes from volatile compounds that are produced from unintended reactions between disinfectants (e.g., chlorine) and organic matter in the water (Li and Blatchley, 2007; Zwiener et al., 2007; Schmalz et al., 2011; Daiber et al., 2016). Body fluids, such as sweat and urine, are among the sources of this organic matter that contribute to the formation of disinfection byproducts (DBPs) (Richardson et al., 2007; Arnaud, 2016; Tang et al., 2016).

According to a 2012 survey of 1000 people in the United States, approximately one in five admitted to "peeing in the pool" (Wiant, 2012), a result consistent with a previous survey conducted in 2009. A recent study published in Environmental Science \& Technology Letters (Blackstock et al., 2017) shows evidence of urine in swimming pools and hot tubs. This new evidence is obtained from the analyses of pool water for a common artificial sweetener, acesulfame potassium (ACE). This sweetener is often used in processed food and is widely consumed; it is chemically stable and passes through the body unchanged into urine (Voltz et al., 1991; von Rymon Lipinski and Hanger, 2001; Buerge et al., 2009; Liu et al., 2014; Tran et al., 2014; $\mathrm{Wu}$ et al., 2014). Therefore, the researchers measured this sweetener as a urinary marker and estimated the equivalent amount of urine in swimming pools and hot tubs. The results indicate the presence of approximately $75 \mathrm{~L}$ of urine in a swimming pool one-third the size of a standard Olympic pool.

Within one day of its online publication on March 1, 2017 (Blackstock et al., 2017), the study was covered by more than 100 news stories in multiple media and languages (Altmetric, 2017). The coverage ranged from scientific press, such as Science Daily (ACS, 2017), to popular press, such as The Guardian (Devlin, 2017), BBC News (2017), CBC News (2017), and CBS News (Gunaratna, 2017). The work even inspired a science communicator to write a poem, educating people "please do not piss into the pool" (Illingworth, 2017). At the time of submission of this commentary on March 5, 2017, there were 172 news stories from 151 news outlets around the world (Altmetric, 2017).

The initial objective of the study by Blackstock et al. (2017) was "to investigate a marker for urine in swimming pools and

\footnotetext{
* Corresponding author.

E-mail addresses: zq_1101@sina.com (Qi Zheng), xingfang.li@ualberta.ca (Xing-Fang Li).
} 
hot tubs". Monitoring human urinary input to swimming pools is important because "urine contains many nitrogenous organics, such as urea, ammonia, amino acids, and creatinine. These compounds can react with disinfectants (e.g., chlorine) in swimming pools to form disinfection byproducts (DBPs)." Most DBPs may not cause adverse health effects at concentrations they are typically found in water. However, studies conducted using higher concentrations of emerging DBPs have shown various toxic effects (Richardson et al., 2007; Fu et al., 2017).

Blackstock et al. (2017) chose acesulfame potassium (ACE) as an indicator of human urinary input on the basis of its widespread consumption and urinary excretion without metabolism. Using a liquid chromatography tandem mass spectrometry technique that they developed, they analyzed more than 250 water samples from 31 swimming pools and hot tubs from two Canadian cities. They also analyzed more than 90 samples of input tap water used to fill the pools and tubs. The concentration of ACE in the swimming pools and hot tubs ranged from 30 to $7110 \mathrm{ng} / \mathrm{L}$, up to 570 times higher than that in the corresponding input tap water (6-15 ng/L).

The authors repeatedly collected and analyzed water samples from two different sized swimming pools, 416,000 L (110,000 U.S. gallons) and $~ 832,000$ L (220,000 U.S. gallons), for three weeks. These pools are about $1 / 6$ and $1 / 3$ the standard Olympic-size. The average concentrations of ACE in these two pools over the three weeks were $156 \mathrm{ng} / \mathrm{L}$ and $210 \mathrm{ng} / \mathrm{L}$, respectively, with a similar relative standard deviation of $15 \%-$ $18 \%$. On the basis of the volume of each pool and the ACE concentration, the authors estimated the total mass of ACE present in the two pools as $65 \mathrm{mg}$ and $176 \mathrm{mg}$, respectively. They further determined an average concentration of ACE in a pooled Canadian human urine sample $(N=20)$ to be $2360 \mathrm{ng} / \mathrm{L}$. Using this average ACE concentration in Canadian urine, they estimated the equivalent volume of urine to be approximately $30 \mathrm{~L}$ in the smaller pool and $75 \mathrm{~L}$ in the larger pool. These represent less than $0.01 \%$ of the total water volume in the pools.

The crude estimation of volume of urine present in the pools was intended to demonstrate the feasibility of using ACE as a marker for urine input. Although the daily analyses of ACE in six replicate water samples from each of the two pools for three weeks provided useful measures of the concentrations of ACE in these pools, concentrations of ACE in other pools could be very different. Many parameters could influence the concentrations of ACE present in the pools. For example, differences in bather load and demographics could contribute to differences in input of ACE into the pools. The size of pools, the amount and rate of water loss from the pools, and the corresponding refill of water into the pools would affect dilution of the input ACE in the swimming pools. Furthermore, the estimation of urine volume from the measured concentrations of ACE in the pools hinges on the concentration of

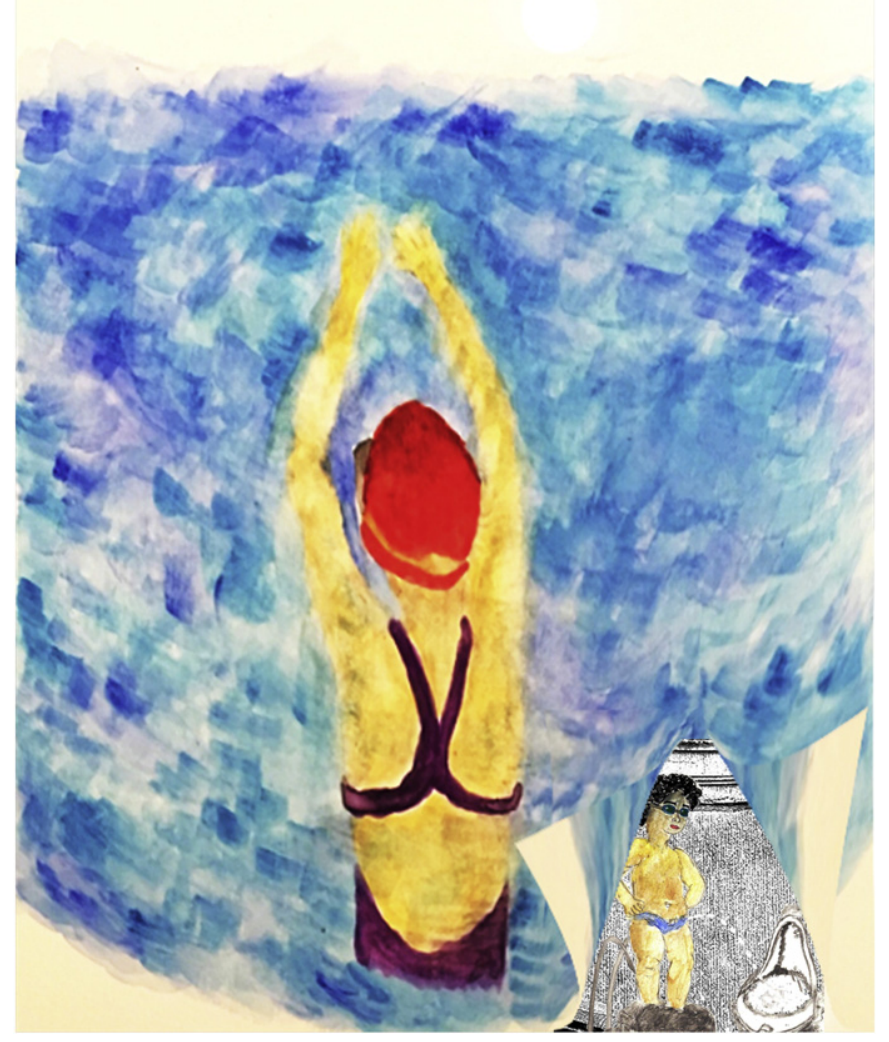

Fig. 1 - Enjoy swimming for active and healthy living and practice good swimmer hygiene. Art design by Yi Li, Edmonton, Alberta, Canada. 
ACE in human urine. Blackstock et al. (2017) measured the concentration of ACE in a composite urine sample from 20 Canadian adults. This composite sample may not be representative of urine samples from other populations. Therefore, it is important to note that the estimated volume of urine input is by no means an accurate measure.

Many news stories of the popular press have such headlines as "how much pee is in our swimming pools?" or "Yes, there is a lot of pee in that public pool", emphasizing $75 \mathrm{~L}$ of urine in a swimming pool smaller than one-third an Olympic-size pool. "Buckets of urine in swimming pools" presented "gross" and "scary" images in the minds of some readers/viewers, which could discourage people from swimming. This was not the purpose of the study. An appropriate public education and public health message should not dwell on how much urine is in the pools, but rather how to promote swimming hygiene and encourage people to enjoy swimming for its health benefits.

When interviewed by the media, both Lindsay Blackstock (the lead author) and Dr. Xing-Fang Li (the corresponding author) of the original study repeatedly emphasized that the benefits of swimming far outweigh the risk of urine in the pools (Engelhaupt, 2017; Brown, 2017; CBC Radio, 2017). They also stressed the importance of public awareness and education to stop peeing in the pools (CBC Radio, 2017). The new research findings on the evidence of urine in swimming pools should be used to promote good swimmer hygiene practice (Fig. 1).

The U.S. Centers for Disease Control and Prevention (CDC) encourages swimmers to practice good hygiene. "Keep the pee, poop, sweat, blood, and dirt out of the water...Shower before you get in the water. Rinsing off in the shower for just 1 minute removes most of the dirt or anything else on your body" (CDC, 2017). Consistent with these recommendations, studies on personal care products in swimming pool water have shown that chemicals in sunscreen and lotions can be precursors to the formation of toxic DBPs (Wang et al., 2013).

A variety of chemicals can be introduced into swimming pools and hot tubs via body fluids, increasing dissolved organic carbon (DOC). The concentration of DOC in swimming pools has been associated with bather load and formation of DBPs. An important measure to minimize the formation of DBPs is to control and reduce DOC (Zheng et al., 2016). Thus, it is critical to keep body fluids out of the pools and minimize the formation of DBPs.

"Swimming and other water-related activities are excellent ways to get the physical activity and health benefits needed for a healthy life" (CDC, 2017). Swimmers have about half the risk of death compared with inactive people (Chase et al., 2008).

For public health protection, we strongly urge practicing good swimmer hygiene, including showering before going into the pools and keeping body fluids out of the pools.

Enjoy swimming and stop peeing in the pools!

\section{R E F E R E N C E S}

ACS (American Chemical Society), 2017. How to Monitor Urine in Pools, by Testing Sweetness. Science Daily (March 1, 2017. Online: https://www.sciencedaily.com/releases/2017/03/ 170301084913.htm. Accessed on March 1, 2017).
Altmetric, 2017. Sweetened Swimming Pools and Hot Tubs. ACS Publications (Online: https://acs.altmetric.com/details/ 16888238/news. Accessed on March 1, 2, and 5, 2017).

Arnaud, C.H., 2016. The chemical reactions taking place in your swimming pool. Chem. Eng. News 94 (31):28-32 http://cen.acs. org/articles/94/i31/chemical-reactions-taking-placeswimming.html.

BBC News, 2017. University of Alberta scientists study urine levels in pools. BBC News (March 2, 2017. Online: http://www.bbc. com/news/world-us-canada-39123085. Accessed on March 2, 2017).

Blackstock, L.K.J., Wang, W., Vemula, S., Jaeger, B.T., Li, X.-F., 2017. Sweetened swimming pools and hot tubs. Environ. Sci. Technol. Lett. http://dx.doi.org/10.1021/acs.estlett. $7 \mathrm{~b} 00043$.

Brown, M., 2017. Science Proves It: People Pee in the Pool. Health Benefits of Swimming Far Outweigh Health Risks of Pee in Public Pools. University of Alberta (March 3, 2017. Online: https://www.ualberta.ca/news-and-events/newsarticles/2017/ march/science-proves-it-people-pee-in-the-pool. Accessed on March 4, 2017).

Buerge, I.J., Buser, H.R., Kahle, M., Müller, M.D., Poiger, T., 2009. Ubiquitous occurrence of the artificial sweetener acesulfame in the aquatic environment: an ideal chemical marker of domestic wastewater in groundwater. Environ. Sci. Technol. 43:4381-4385. http://dx.doi.org/10.1021/ es900126x.

CBC (Canadian Broadcasting Corporation), 2017. Artificial sweetener key component in University of Alberta pee-in-pool research. March 2, 2017. Online: http://www.cbc.ca/news/ canada/edmonton/pee-swimming-pool-university-albertaresearch-urine-sweetener-1.4006972. (Accessed on March 2, 2017).

CBC Radio, 2017. Quirks \& Quarks with Bob McDonald. March 4, 2017. Online: http://www.cbc.ca/radio/quirks/don-t-pee-inthepool-bees-play-ball-and-lucid-dreaming-1.4008562, and podcast at: http://www.cbc.ca/radio/podcasts/scienceandtech/quirks-quarks/ and podcast download: http:// podcast.cbc.ca/mp3/podcasts/quirksaio_20170304_88956.mp3. (Accessed on March 4, 2017).

CDC (U.S. Centers for Disease Control and Prevention), 2017. Healthy swimming: steps of healthy swimming. Online: https://www.cdc.gov/healthywater/swimming/swimmers/ steps-healthy-swimming.html. (Accessed March 2, 2017).

Chase, N.L., Sui, X., Blair, S.N., 2008. Swimming and all-cause mortality risk compared with running, walking, and sedentary habits in men. Int. J. Aquat. Res. Educ. 2 (3):213-223. http:// scholarworks.bgsu.edu/ijare/vol2/iss3/3/.

Daiber, E.J., DeMarini, D.M., Ravuri, S.A., Liberatore, H.K., Cuthbertson, A.A., Thompson-Klemish, A., Byer, J.D., Schmid, J.E., Afifi, M.Z., Blatchley III, E.R., Richardson, S.D., 2016. Progressive increase in disinfection byproducts and mutagenicity from source to tap to swimming pool and spa water: impact of human inputs. Environ. Sci. Technol. 50:6652-6662. http://dx.doi.org/10.1021/acs.est.6b00808.

Devlin, H., 2017. How much pee is in our swimming pools? New urine test reveals the truth. The Guardian (March 1, 2017. Online: https://www.theguardian.com/science/2017/mar/01/ how-much-pee-is-in-our-swimming-pools-new-urine-testreveals-the-truth. Accessed on March 2, 2017).

Engelhaupt, E., 2017. Just how much pee is in that pool? NPR News (March 1, 2017. Online: http://www.npr.org/sections/healthshots/2017/03/01/517785902/just-how-much-pee-is-in-thatpool? $\mathrm{ft}=\mathrm{nprml} \& \mathrm{f}=$. Accessed on March 1, 2017)

Fu, K.Z., Li, J., Vemula, S., Moe, B., Li, X.-F., 2017. Effects of halobenzoquinone and haloacetic acid disinfection byproducts on human neural stem cells. J. Environ. Sci. http:// dx.doi.org/10.1016/j.jes.2017.02.006. 
Gunaratna, S., 2017. How much urine is in a swimming pool? Study finds disturbing answer. CBS News (March 2, 2017. Online: http://www.cbsnews.com/news/how-much-urine-isin-a-swimming-pool-canadian-study-has-the-answer/. Accessed on March 2, 2017).

Illingworth, S., 2017. A piscine problem. The Poetry of Science. Online:. http://thepoetryofscience.scienceblog.com/398/apiscine-problem/ (Accessed on March 3, 2017).

Li, J., Blatchley III, E.R., 2007. Volatile disinfection byproduct formation resulting from chlorination of organic-nitrogen precursors in swimming pools. Environ. Sci. Technol. 41: 6732-6739. http://dx.doi.org/10.1021/es070871+.

Liu, Y., Blowes, D.W., Groza, L., Sabourin, M.J., Ptacek, C.J., 2014. Acesulfame-K and pharmaceuticals as co-tracers of municipal wastewater in a receiving river. Environ. Sci. Process. Impacts 16: 2789-2795. http://dx.doi.org/10.1039/C4EM00237G.

Richardson, S.D., Plewa, M.J., Wagner, E.D., Schoeny, R., DeMarini, D.M., 2007. Occurrence, genotoxicity, and carcinogenicity of regulated and emerging disinfection by-products in drinking water: a review and roadmap for research. Mutat. Res. 636: 178-242. http://dx.doi.org/10.1016/j.mrrev.2007.09.001.

von Rymon Lipinski, G.-W., Hanger, L.Y., 2001. Acesulfame K. In: O’Brien Nabors, L. (Ed.), Alternative Sweeteners, third ed. 2001. Marcel Dekker, New York, pp. 13-30.

Schmalz, C., Frimmel, F.H., Zwiener, C., 2011. Trichloramine in swimming pools - formation and mass transfer. Water Res. 45 : 2681-2690. http://dx.doi.org/10.1016/j.watres.2011.02.024.

Tang, Y., Xu, Y., Li, F., Jmaiff, L., Hrudey, S.E., Li, X.-F., 2016. Nontargeted analysis of peptides and disinfection byproducts in water. J. Environ. Sci. 42:259-266. http://dx.doi.org/10.1016/j. jes.2015.08.007.
Tran, N.H., Hu, J., Li, J., Ong, S.L., 2014. Suitability of artificial sweeteners as indicators of raw wastewater contamination in surface water and groundwater. Water Res. 48:443-456. http:// dx.doi.org/10.1016/j.watres.2013.09.053.

Voltz, M., Christ, O., Eckert, H.G., Herok, J., Kellner, H.-M., Rupp, W., 1991. Kinetics and biotransformation of acesulfame K. In: Mayer, D.G., Kemper, F.H. (Eds.), Acesulfame-K. 1991. Marcel Dekker, New York, pp. 7-26.

Wang, W., Qian, Y., Boyd, J.M., Wu, M., Hrudey, S.E., Li, X.-F., 2013. Halobenzoquinones in swimming pool waters and formation from personal care products. Environ. Sci. Technol. 47: 3275-3282. http://dx.doi.org/10.1021/es304938x.

Wiant, C., 2012. New public survey reveals swimmer hygiene attitudes and practices. Int. J. Aquat. Res. Educ. 6 (3):4 (http:// scholarworks.bgsu.edu/ijare/vol6/iss3/4).

Wu, M., Qian, Y., Boyd, J.M., Hrudey, S.E., Le, X.C., Li, X.-F., 2014 Direct large volume injection ultra-high performance liquid chromatography-tandem mass spectrometry determination of artificial sweeteners sucralose and acesulfame in well water. J. Chromatogr. A 1359:156-161. http://dx.doi.org/10.1016/j. chroma.2014.07.035.

Zheng, Q., Yang, X., Deng, W., Le, X.C., Li, X.-F., 2016. Characterization of natural organic matter in water for optimizing water treatment and minimizing disinfection by-product formation. J. Environ. Sci. 42:1-5. http://dx.doi.org/ 10.1016/j.jes.2016.03.005.

Zwiener, C., Richardson, S.D., DeMarini, D.M., Grummt, T., Glauner, T., Frimmel, F.H., 2007. Drowning in disinfection byproducts? Assessing swimming pool water. Environ. Sci. Technol. 41:363-372. http://dx.doi.org/10.1021/es062367v. 